\title{
The Scribe Effect: the Impact of a Pre-matriculation Experience on Subsequent Medical School Education
}

\author{
Robert Waller $^{1} \cdot$ Ndifreke Ekpa $^{2} \cdot$ Lawrence Kass $^{1} \mathbb{D}$
}

Accepted: 14 September 2021 / Published online: 21 September 2021

(c) International Association of Medical Science Educators 2021

\begin{abstract}
Medical scribes have been utilized since the 1970s but have been in ever-increasing demand over the past 25 years. The reasons for this growth have been well documented, with positive impacts on provider well-being, patient satisfaction, clinical efficiency, and revenue generation. Many aspiring healthcare providers become medical scribes during or immediately after college, believing it will provide them with helpful experience and increase their chances of gaining entrance into medical education. However, little data exists to justify those beliefs. Through written surveys and semi-structured interviews, we found that scribes feel that their experience shaped their futures in medicine in two broad themes, specifically confirming their commitment to medicine (with subthemes of specialty choice, establishing mentorship, and exposure to difficult topics) and the essential skills of a physician (with subthemes of communication, professionalism, history and physical, terminology and jargon, and clinical reasoning). Understanding the impact of a scribe experience may provide medical school admissions personnel a more thorough sense of the scribe's strengths and likelihood of success in training, and should generate testable hypotheses for further studies into the learning processes of medical scribes.
\end{abstract}

Keywords Medical student $\cdot$ Scribes $\cdot$ Qualitative $\cdot$ Competency $\cdot$ Communication $\cdot$ Clinical reasoning

\section{Introduction}

As defined by the Joint Commission, a medical scribe is an unlicensed person hired to enter information into the Electronic Health Record (EHR) or chart at the direction of a physician or other licensed practitioner. They cannot act independently but can document the previously determined clinician's dictation and/or activities. While reports on the use of medical scribes date back to the mid-1970s and early 1980s [1,2], the ever-increasing demands upon provider time and increasing complexity of mandated documentation have resulted in a rapid expansion of the use of scribes over the last two decades [3]. While the training can vary widely, scribes typically receive several dozen hours of preparation, generally from a company that recruits, trains, and then markets them to providers. This training includes

Lawrence Kass

lkass@pennstatehealth.psu.edu

1 Department of Emergency Medicine, Penn State Milton S. Hershey Medical Center, 500 University Dr, PO Box 850, Hershey, PA, USA

2 Penn State College of Medicine, Hershey, USA information on medical terminology, medical physiology, and documentation elements. The literature shows that the use of scribes can have significant positive impact on provider well-being, patient satisfaction, clinical efficiency, and revenue generation [3-13].

We have been using scribes in our Emergency Department since 2015 and currently employ about 25 scribes. Our anecdotal observations in talking with them has been that they are overwhelmingly in their final years of college or have just recently graduated from college, and that many of them are in the process of applying to medical school. They often state that shadowing experiences, while important to application committees, are increasingly difficult to arrange. And finally, they state they think scribing is good preparation for medical school. One of us recently wrote a commentary describing these perceptions from the perspective of having been a scribe [14].

This raises a question. What is the educational impact of having been a scribe on a medical student? Scribe companies are explicit in that the "primary purpose of a scribe is to facilitate the provider's workflow" and that "(m)edical providers are allowed to teach, but it would be on the medical provider's own time and there should be no expectation on the part 
of the scribe" [15]. Casual conversation with scribes reveals that they do this job not only for the money, but because they also believe it will either help them get into medical school or prepare them to be more successful once they get there.

The perception that it improves their ability to gain acceptance to medical school has some support in the literature. DeWitt and Harrison [16] noted that a history of having been a scribe significantly increased (odds ratio 1.61) the likelihood of being accepted to one medical school. But to our knowledge this has not been reported elsewhere and the role that scribing experience plays in the evaluation by an acceptance committee is unclear.

The belief that having been a scribe improves a student's ability to succeed in medical school has little scientific foundation in the literature beyond some reports on performance on standardized exams and clerkship grades [17-22]. We are particularly interested in the perceptions of students who have been scribes. Therefore, we have chosen a qualitative methodology as this is best positioned to examine how people make meaning of an experience [23]. Our aim was to perform an investigation into the impact of having been a medical scribe upon a student's future experience in medical school, which we are calling the "scribe effect."

\section{Materials and Methods}

We performed a qualitative study to identify perspectives and themes common to former scribes currently in medical school (i.e., areas in which they felt they were influenced by their experiences as a medical scribe and how this affected their medical school years). Participant recruitment took place among current students at the Penn State Hershey College of Medicine (COM) during academic year 2020-2021. The original approved recruitment methodology involved an email sent broadly to the COM student listserv by the participating medical student researcher, placement of fliers oncampus, and by word-of-mouth propagation within the classrooms. However, as a result of the COVID-19 pandemic, students were not physically on-campus for almost all of the study period, and so while fliers were still posted, virtually all responses came via email. After a student expressed interest in the project, they were sent a brief survey to determine eligibility. Study data were collected and managed using REDCap electronic data capture tools hosted at Penn State Health Milton S. Hershey Medical Center and Penn State College of Medicine. REDCap (Research Electronic Data Capture) is a secure, Web-based application designed to support data capture for research studies. Participants were excluded from the study if they had a history of previous medical experience, such as EMT, paramedic, nurse, nurse assistant, physician assistant, nurse practitioner, etc., as these other professions/experiences might confound observations on the shaping of the physician. After identification of the eligible participants, students were sent a link to an online interface and individual (via Zoom) interviews were scheduled and then conducted using semi-structured interviews with predetermined, open-ended questions with additional exploration of specific themes as needed (Appendix).

The questions were developed by the investigators based on preliminary informal discussions with current scribes in our department. They were then reviewed and revised by a departmental research committee prior to submission to the hospital IRB. Interviews were recorded and then transcribed. Upon completion of the transcription, the audio recordings were deleted. Written data was de-identified and only the participant's year in training was retained. Transcripts were coded by the senior author using NVivo software (QSR International, Version 12, released 2018). The codebook was reviewed by all co-authors and discrepancies resolved. The college's Human Subjects Protection Office evaluated the study and determined that the study met the criteria for exempt research according to the policies of the institution and the provisions of applicable federal regulations.

\section{Results}

Twelve students were ultimately interviewed. Of them, nine were in their first- or second-year of medical school, while three were in their final year of school. Six of the participants did their scribing exclusively in the emergency department. Two worked in both the emergency department and clinics. Four scribed exclusively in outpatient clinics. They worked an average of 1.4 years (range 1-2.5) as scribes. All started while in college and stopped working just prior to starting medical school. We completed the study after coding the twelfth transcript (our final sample size), as no new themes were identified after the tenth transcript, indicating that we had achieved data saturation [23]. This sample size was consistent with expectations for this methodology [24].

\section{Themes}

We identified two major themes, each with several subthemes.

\section{Theme 1 -Confirming a Commitment to Medicine}

Eight of the participants spontaneously offered the observation that serving as a scribe confirmed their desire to become a physician. The remaining four also supported that statement when asked about it. For example, one participant noted:

"This was exposure to a job you want to pursue. After being a scribe, I felt more confident I knew what being 
a doctor entailed and that I wanted to do that. I was confident in knowing what I was getting myself into and what that would look like when I reached my profession and also exposure to the field and just kind of getting immersed in it. With shadowing you're kind of more so just in the background observing, but when you're scribing you're part of the team and it's kind of a different dynamic and more immersive in that way...I also knew some people who did scribing and then realized they didn't want to be doctors." (4th year student, Emergency Department scribe)

Within that theme, three subthemes emerged:

Subtheme 1-Specialty Choice.

Nine of the participants noted that the exposure to certain specialties gave them insight into the choices for future careers. While most expressed an interest in pursuing the specialty in which they scribed, others noted that their exposure to the schedule or work environment of that specialty actually discouraged them from considering that field.

"I was a scribe in three different clinics: neuro, ortho, and pediatrics. I got to see what each one was like. I might not pick one of those three for my residency, but I've got a much better idea of what I'm looking for and what's important to me in a specialty choice." (1st year student, clinic scribe)

Among those that commented on specialty selection, this was the typical response. They learned about a specialty. But perhaps more importantly, they started to understand what was important to them in choosing a specialty:

"When I was in college, I wanted to be a surgeon. I thought that would be a good choice for me because I'm good with my hands. But when I got to watch and talk with the doctors, I got to realize there was a lot more that goes in to that decision. It's also the personality and lifestyle that have to fit." (2nd year student, emergency department and clinic scribe)

Subtheme 2-Mentorship.

All of the participants noted the positive impact of working with experienced physicians who took pleasure in explaining what they were doing to the scribes and, in many cases, talked with them about being a physician and the process of applying to medical school.

"I worked with a lot of younger physicians and once they learned I was applying to medical school, they really seemed to go out of their way to talk with me about what they were thinking. They also talked with me about what it meant to be a doctor. Two of them even offered to write me letters of recommendation. I let both of them know that I ultimately chose Penn
State." (1st year student, Emergency Department scribe)

Six of the students noted that supervising physicians have written letters of recommendation for them, and two described their physician supervisors as having remained as informal mentors.

Subtheme 3-Difficult Topics.

For almost all of these participants, being a scribe was their first exposure to difficult situations such as death and homelessness/poverty. Being able to watch how an experienced physician approached and handled these situations was reassuring and increased their confidence that they would be able to do this eventually too. This example shows how impacted the students were by these experiences:

"I had never seen a dead person before this. I had no idea what you were supposed to do or how to act. But being able to be in the background and watch how the doctor spoke with the family made it a lot easier for me when we started talking about that in med school. I was also really surprised at how important it was to understand the patient's social or economic situation. I guess I sort of already knew that. But seeing how often it affected what the doctor could do and how important it was to be aware of that really struck me." (1st year student, Emergency Department scribe)

\section{Theme 2-Physician Skills}

All of the participants related that being a scribe gave them insight into, and in many cases practice with, the skills taught and evaluated in the first years of medical school. Their observations can be grouped in to five subthemes: communication, professionalism, the history and physical exam $(\mathrm{H} \& \mathrm{P})$, terminology, and clinical reasoning. All of the students reported that they found the transition to medical school easier, and felt they were more successful in many of their courses, because of their early exposure to these core skills. The three senior medical students agreed with these comments about early success, but noted that the differences between them and their (non-scribe) classmates narrowed, and essentially vanished, by the time they started their fourth year.

Subtheme 1-Communication.

This theme describes the students developing ability to effectively communicate with patients and colleagues. The following quote provides an example, but several others made similar comments:

"I'm definitely better at communicating with patients, colleagues, and doctors from having been a scribe. I think a lot of that came from seeing different approaches from different physicians, some bad and 
some good and seeing which ones were more effective." (4th year student, clinic scribe)

Subtheme 2-Professionalism.

The theme of professionalism relates to the students developing ability to observe (and subsequently adopt) the behaviors and attitudes expected of a physician. All of the participants noted that they gained insight into how a physician should act by being a scribe. One participant noted:

"As a scribe, you get to see how the doctor works with and treats everyone else in the department... the nurses, the techs and of course the patients. I've seen what I want to do and what I don't want to do. I've learned some "soft skills" that you only learn by observation." (1st year student, Emergency Department scribe)

Another participant alluded to the hidden curriculum of medical training when they noted:

"I saw how a lot of different doctors acted. I hate to say it, but some of them were definitely a bit cynical and I think maybe burnt out. They all said they enjoyed taking care of patients, but you could see it when they picked up certain charts. They would roll their eyes and make some flippant comment about why (the patient was) here and not at their PCP (primary care physician). I don't want to do that." (2nd year student, Emergency Department scribe)

Subtheme 3-the H\&P.

All of the interviewees observed how scribing improved their ability to organize a history and physical exam and subsequently document it. Many further noted a greater understanding of required elements for billing and coding and an ability to generate differential diagnoses.

"My advisor took one look at my notes and said 'you were a scribe, right?' It very much helps to know what a SOAP note looks like and how to write one. I had the format down pat. Also on differentials. It was very helpful for me to have a mental list of common things that go together. If I saw a chest pain, you automatically key in on MI, PE and other stuff that you might not even gotten to on units yet. The expectation for differentials on FPCC (a preclinical course that teaches how to perform H\&P's and write notes) is very high and I don't know how you would do it without this experience." (2nd year student, clinic scribe)

While their comments here mostly pertained to the positive aspects of observing experienced clinicians, two students did note that there was a downside to copying experienced providers. One noted:
"I tended to ask too many close-ended questions because I focused too early on the specifics of a diagnosis. I had to unlearn certain abbreviations and styles that my attendings used." (2nd year student, Emergency Department scribe)

Subtheme 4-Terminology.

The theme of terminology refers to the students' skill with the terms, abbreviations, and jargon used in medicine. All of the students noted that the training provided by their scribe company and the subsequent experience transcribing physician dictations gave them skill with this. One participant noted:

"Scribing definitely helped me with that...made me more comfortable with the words in the work setting. Like knowing differences between words. A couple of common medications. It also helped me with anatomy. It helps to know that lateral means to the outside." (2nd year student, Emergency Department scribe)

This same participant also talked about knowledge acquisition in general when they went on to say that:

“(Y)ou learn by osmosis...I wasn't trying to learn drugs and medication side-effects, but I did just by being there." (2nd year student, Emergency Department scribe)

Subtheme 5-Clinical Reasoning.

The subtheme of clinical reasoning refers to the learning of the thought processes used by physicians to create differential diagnoses and develop diagnostic and management strategies. Ten of the participants noted scribing helped them with this. One student put it well by stating:

"Learning differential diagnosis was easy. Learning the thought processes that go into medical decision making is exactly what I was seeing when I was scribing. I didn't get that shadowing or in any classes I took. I knew what tests needed to be ordered. If a patient came in with chest pain, I knew the doctor was going to order things like an EKG, a chest $\mathrm{x}$-ray, a d-dimer and a troponin. I didn't know what a d-dimer or a troponin were...I barely knew what a PE or an MI was, but when we got to that in my Cardiology block, it made a lot more sense." (2nd year student, Emergency Department scribe)

\section{Discussion}

The educational impact of having been a scribe, what we are calling the "scribe effect," falls into two broad themes: solidifying the student's commitment to pursuing a career 
in medicine, and early exposure and skill development in many of the critical tasks taught to developing physicians.

These observations are consistent with either a social cognitivist perspective or a community of practice perspective of adult education [25]. The former posits that learning occurs through observation of others, the cognitive processing of those observations, and the experiential learning that comes from witnessing outcomes and getting feedback in a learning environment. The latter focuses on how learners, through observation and practice, move from the margins of a practicing community closer and closer to its center. Therefore, it is possible to argue that scribes, through their close observation of experienced providers providing care in a clinical setting, coupled with feedback on their documentation of those observations, learn the knowledge, skills, and attitudes necessary to succeed in the early tasks of medical school training, and are perhaps already closer to the center of the community of practice at the beginning of medical school than their peers.

However, while there is a robust literature on the impact of scribes on the clinicians and patients with whom they work, research examining this educational effect on the scribes is scant. Hewlett [17] reported on an electronic survey of 333 students at one medical school and found that $34 \%$ of them had some scribe experience. While the majority of them noted that their scribe experience helped them "somewhat" or "a lot" with their pre-clerkship work, an analysis of covariance (ANCOVA) found no statistically significant difference in outcome metrics such as USMLE (United States Medical Licensing Examination) Step 1 scores, class rank, assessment of note writing ability, or self-reported wellbeing. This finding contrasts with that of Shah et al. [18] who found a statistically significant improvement in both Step 1 and Step 2 USMLE scores for those with "pre-matriculation clinical experience" among a single class of medical students at one school. It must be noted however that Shah did not assess the impact of having been a scribe separately from the other forms of "pre-matriculation experience" (e.g., having been an $\mathrm{RN} / \mathrm{LPN} / \mathrm{NP}, \mathrm{PA}$, or EMT/paramedic) and it is not possible to conclude from this that scribing itself is linked with subsequent improved exam performance. Interestingly, Strowd et al. [19] found no difference in MCAT, USMLE Step 1 or USMLE Step 2 CK scores between those with and without prior paid experience but did find higher NBME subject exam scores, clinical clerkship scores, and cumulative year-3 performance and concluded that the prior experience allowed these students to "outperform their peers in the clinical environment." Though twenty of the 49 students surveyed in their study were former scribes, the remainder had other prior experiences and it is not possible to attribute the findings solely to scribing.

Lastly, three studies and one commentary looked at student perspectives of the impact of scribing. Lin et al. [20] reported on 5 years of experience with a new scribe fellowship program and found that the scribes reported feeling better positioned for professional schooling. Ely and Allen [21] recently reported on interviews of 8 scribes and 9 medical students who had been scribes and noted that, while they were not convinced that having been a scribe made a difference in their ability to gain entrance to medical school, they did believe that the role had helped them in learning medical terminology, communication skills, and the practice of medicine. Skelly et al. [22] surveyed 214 medical students and found that those with prior scribe experience had statistically significant higher confidence in their clinical note writing and history taking than non-scribes and also felt that having been a scribe impacted their medical knowledge, communication, and healthcare environment functioning. Abdulahad et al. [14] published a commentary describing the personal experience of three former scribes and how it prepared them for becoming physicians by exposing them to critical skills necessary for success as a physician and giving them a realistic picture of what practice is like. Hence, while the objective outcome data may be conflicting, the available subjective data is more uniform on the positive impact of scribing.

\section{Conclusions}

We have demonstrated that, at least from the perspective of our purposeful sample of students, that there is a "scribe effect": learning that occurs while being a scribe that benefits the students during their early years of medical school. Further, this learning falls into two broad themes, solidifying their commitment to medicine and providing them with valuable experience with many of the skills taught (and tested) in medical school.

Qualitative research, while it can give insight into the perceived impact of an experience and generate hypotheses, is typically not designed to be generalizable. Outcome-based quantitative research would be useful in validating these observations and potentially generating evidence-based changes in practice. The observations described above, however, do support the following recommendations:

Aspiring medical students should be encouraged to work as a scribe. Scribes certainly feel this improves their performance once there. Some existing evidence suggests that it does increase the likelihood of acceptance [16] though the data on objective performance is inconclusive [19-25].

Second, medical schools (if they are not doing so already) should include scribe experience as a positive factor in assessing applicants for admission with a weight equivalent to, if not exceeding, that given to shadowing experience.

Third, teaching hospitals affiliated with medical schools should consider developing (or expanding) scribe programs 
as a conduit to recruiting and training highly-qualified candidates for medical school admission.

Finally, this hypothesis should be tested. The "scribe effect" indicates that having been a scribe results in a positive educational effect for those who subsequently enter medical school. The data from this qualitative study indicate that, at least at our medical school, students who had been scribes believe that this experience gave them important insights into the attitudes and behaviors expected of a physician, and preparation in terminology, documentation, and format of a history and physical that made them more successful in their first years of medical school. A quantitative study, analyzing the performance of former scribes on typical measures of student knowledge, skill, and/or attitudes such as OSCEs (Objective Structured Clinical Evaluation), USMLE tests, or faculty assessments during clinical rotations, as compared to matched cohorts of non-scribe students, can test those beliefs and provide data as to whether the "scribe effect" has significant impact in the acquisition of these important traits.

\section{Appendix}

\section{Scribe effect interview questions}

\section{Demographic questions:}

When were you a scribe?

How many hours a week did you workwe?

How many years of experience do you have?

What year are you currently in your training in medical school?

\section{Effect questions:}

How did your experience as a scribe impact your (first, second, third, fourth) year of medical school? Please elaborate. Can you give an example?

\section{Specific topics that may be asked if the participant does not bring them up:}

Medical terminology and healthcare jargon

Use and interpretation of laboratory and imaging modalities

Presentation of patients (sick vs. not sick)

History and physical exam skills

The way doctor's think through things (decision-making and logic)

Documentation format (History and Physical)

Communication skills (e.g., rapport-building, framing and reason-giving, listening, etc.)
Specific anecdotes of how being a scribe helped during medical school

Other (e.g., computer/typing skills)

\section{Winding up questions:}

What do you perceive to be the benefits of serving as a scribe?

(Were there any unexpected benefits from being a medical scribe?)

What do you perceive to be the drawbacks of serving as a scribe?

(Were there any unexpected drawbacks from being a medical scribe?)

What advice would you give to future medical students considering serving as a scribe before applying to medical school?

Author Contributions All authors contributed to the study conception and design. Material preparation, data collection, and analysis were performed by Robert Waller, Ndifreke Ekpa, and Lawrence Kass. The first draft of the manuscript was written by Lawrence Kass and all authors commented on previous versions of the manuscript. All authors read and approved the final manuscript.

Funding This study was funded by an internal departmental grant.

Availability of Data and Material The datasets generated during and/ or analyzed during the current study are not publicly available due to privacy considerations for the subjects but are available from the corresponding author on reasonable request.

\section{Declarations}

Ethics Approval The Penn State University College of Medicine Human Subjects Protection Office evaluated the study and determined that the study met the criteria for exempt research according to the policies of the institution and the provisions of applicable federal regulations.

Consent to Participate Verbal informed consent was obtained from all individual participants included in the study.

Consent for Publication All participants consented to the submission of their transcribed statements to the journal.

Conflict of Interest The authors declare no competing interests.

\section{References}

1. Allred RJ, Ewer S. Improved emergency department patient flow: five years of experience with a scribe system. Ann Emerg Med. 1983;12(3):162-3.

2. Witt RC, Haedtler DR. Nurse-scribe system saves time in the E.D. J Emerg Nurs. 1975;1(1):23-7. 
3. Shultz CG, Holmstrom HL. The use of medical scribes in health care settings: a systematic review and future directions. J Am Board Fam Med. 2015;28:371-81.

4. Heaton HA, Castaneda-Guarderas A, Trotter ER, et al. Effect of scribes on patient throughput, revenue, and patient and provider satisfaction: a systematic review and meta-analysis. Am J Emerg Med. 2016;34:2018-28. https://doi.org/10.1016/j.ajem.2016.07.056.

5. Heaton HA, Nestler DM, Lohse CM, Sadosty AT. Impact of scribes on emergency department patient throughput one year after implementation. Am J Emerg Med. 2017;35:311-4. https:// doi.org/10.1016/j.ajem.2016.11.017.

6. Bastani A, Shaqiri B, Palomba K, et al. An ED scribe program is able to improve throughput time and patient satisfaction. Am J Emerg Med. 2014;32:399-402. https://doi.org/10.1016/j.ajem.2013.03.040.

7. Cowan TL, Dunlop WA, Ben-Meir M, et al. Emergency consultants value medical scribes and most prefer to work with them, a few would rather not: a qualitative Australian study. Emerg Med J. 2018;35(1):12-7. https://doi.org/10.1136/emermed-2017-206637.

8. Gellert GA, Ramirez R, Webster SL. The rise of the medical scribe industry: implications for the advancement of electronic health records. JAMA. 2015;313:1315-6. https://doi.org/10.1001/ jama.2014.17128.

9. Gidwani R, Nguyen C, Kofoed A, et al. Impact of scribes on physician satisfaction, patient satisfaction, and charting efficiency: a randomized controlled trial. Ann Fam Med. 2017;15(5):427-33. https://doi.org/10.1370/afm.2122.

10. Imdieke BH, Martel ML. Integration of medical scribes in the primary care setting: improving satisfaction. J Ambul Care Manag. 2017;40:17-25. https://doi.org/10.1097/JAC.0000000000000168.

11. Pozdnyakova A, Laiteerapong N, Volerman A, et al. Impact of medical scribes on physician and patient satisfaction in primary care. J Gen Int Med. 2018;33(7):1109-15. https://doi.org/10.1007/ s11606-018-4434-6.

12. Shuaib W, Hilmi J, Caballero J, et al. Impact of a scribe program on patient throughput, physician productivity, and patient satisfaction in a community-based emergency department. Health Inform J. January 2021; 1:1460458217692930. https://doi.org/10.1177/ 1460458217692930.

13. Zallman L, Finnegan K, Roll D, et al. Impact of medical scribes in primary care on productivity, face-to-face time, and patient comfort. J Am Board Fam Med. 2018;31(4):612-9. https://doi. org/10.3122/jabfm.2018.04.170325.
14. Abdulahad D, Ekpa N, Baker E, et al. Being a medical scribe: good preparation for becoming a doctor. Med Sci Educ. 2020;30:569-72. https://doi.org/10.1007/s40670-020-00937-w.

15. ScribeAmerica website, www.scribeamerica.com/faq, accessed March 28, 2021.

16. DeWitt D, Harrison LE. The potential impact of scribes on medical school applicants and medical students with the new clinical documentation guidelines. J Gen Intern Med. 2018;33(11):20024. https://doi.org/10.1007/s11606-018-4582-8.

17. Hewlett WH, Woleben CM, Alford J, et al. Impact of scribe experience on undergraduate medical education. Med Sci Educ. 2020;30:1363-6. https://doi.org/10.1007/s40670-020-01055-3.

18. Shah R, Johnstone C, Rappaport D, et al. Pre-matriculation clinical experience positively correlates with Step 1 and Step 2 scores. Adv Med Educ Pract. 2018;25(9):707-11. https://doi.org/10.2147/AMEP. S173470.

19. Strowd LC, Gao H, O'Brien MC, et al. Prematriculation healthcare employment predicts success in clerkship environment. Med Sci Educ. 2020;30:211-7. https://doi.org/10.1007/s40670-019-00859-2.

20. Lin S, Duong A, Nguyen C, Teng V. Five years' experience with a medical scribe fellowship: Shaping future health professions students while addressing provider burnout [published online ahead of print, 2020 Sep 22]. Acad Med. 2020. https://doi.org/10.1097/ ACM.0000000000003757.

21. Ely RM, Allen BR. Medical scribes in the Emergency Department: the scribes' point of view. Ochsner J. Dec 2019;19(4):319-328. https://doi.org/10.31486/toj.18.0176.

22. Skelly K, Weerasinghe S, Daly J, et al. Impact of medical scribe experiences on subsequent medical student learning. Med Sci Educ. 2021;31:1149-56. https://doi.org/10.1007/s40670-021-01291-1.

23. Creswell, JW and Creswell, JD. Research design: qualitative, quantitative, and mixed methods approaches Fifth edition. I Los Angeles : SAGE; 2018. pp. 179-212.

24. Lowe A, Norris AC, Farris AJ, Babbage DR. Quantifying thematic saturation in qualitative data analysis. Field Methods. 2018;30(3):191-207. https://doi.org/10.1177/1525822X17749386.

25. Merriam, SB and Bierema LL. Adult learning: linking theory and practice. San Francisco: Wiley \& Sons; 2014. pp. 35-36, 120-123.

Publisher's Note Springer Nature remains neutral with regard to jurisdictional claims in published maps and institutional affiliations. 